Rev. Int. Contam. Ambie. 35 (4) 945-956, 2019

DOI: 10.20937/RICA.2019.35.04.13

\title{
REMOCIÓN DE CROMO TRIVALENTE EN AGUAS RESIDUALES DE CURTIEMBRES MEDIANTE UN PROCESO BIÓTICO-ABIÓTICO BASADO EN EL USO DE Yarrowia lipolytica Y Candida fluviatilis
}

Removal of trivalent chromium in tannery wastewater by biotic-abiotic process based on Yarrowia lipolytica and Candida fluvialitis

\author{
Didier Erlinton ORDOÑEZ BURBANO y Neyla BENÍTEZ-CAMPO*
}

Universidad del Valle, Cali, Colombia. Calle 13 No. 100-00. Código postal 76001, Colombia

*Autora de correspondencia: neyla.benitez@correounivalle.edu.co

(Recibido: marzo 2018; aceptado: febrero 2019)

Palabras clave: asociación microbiana, biorreactor, curtido de pieles, levaduras, microorganismos acidófilos

\section{RESUMEN}

Las curtiembres son reconocidas por generar residuos tóxicos altamente contaminantes, entre ellos el cromo, metal que recibe gran atención por los efectos negativos sobre la biota y los seres humanos. A pesar de existir diferentes métodos físicos y químicos para su tratamiento, son poco acogidos por los altos costos y la complejidad de las tecnologías. Con el propósito de evaluar la capacidad de remoción de cromo trivalente con microorganismos provenientes de aguas residuales del curtido de pieles, se aislaron microrganismos acidófilos, cromo resistentes, en medios de cultivo preparados a partir de las sales requeridas para el proceso del curtido. Posteriormente, se seleccionaron dos levaduras nativas, por su mayor abundancia, identificadas como Yarrowia lipolytica y Candida fluviatilis, que fueron utilizadas en conjunto para inocular los biotratamientos tipo lote, que se hicieron en matraces Erlenmeyer empacados con arena de 2.5 a $6 \mathrm{~mm}$ de grosor, que contenían agua del curtido, a una concentración de $1021 \mathrm{mg} \mathrm{Cr}$ (III)/L. Se incluyeron testigos químicos, físicos y biológicos. Después de 21 días de incubación en los biotratamientos se removió $97.5 \%$ del cromo con aumento del pH. Esta investigación demostró la importancia de la interacción de factores bióticos y abióticos para potenciar la remoción del cromo en aguas ácidas provenientes de curtiembres. Los resultados son novedosos para el tratamiento de efluentes del curtido, al disminuirse la concentración de cromo trivalente mediante un método biológico que a su vez aumenta el $\mathrm{pH}$, alcanzando valores permisibles y aprovechando la biodiversidad propia de estos efluentes, beneficios que posibilitan su posterior utilidad a mayor escala.

Key words: microbial association, bioreactor, tanning of hides, yeasts, acidophilic microorganisms

\begin{abstract}
Tanneries are recognized for generating highly polluting toxic wastes, including chromium, a metal that receives great attention due to the negative effects on biota and humans. Despite the existence of different physical and chemical methods for its treatment, these are not well received due to the high costs and complexity of the technologies. In order to evaluate the removal capacity of trivalent chromium with microorganisms from wastewater from leather tanning, acidophilic, chromium-resistant microorganisms
\end{abstract}


were isolated in culture media prepared from the salts required for the tanning process. Subsequently, two native yeasts were selected, by their greater abundance, identified as Yarrowia lipolytica and Candida fluviatilis, which were used together to inoculate the batch type biotreatments, which consisted of Erlenmeyer flasks, packed with sand of 2.5 to $6 \mathrm{~mm}$ thick, containing tanning water at a concentration of $1021 \mathrm{mg} \mathrm{Cr}$ (III) / L, chemical, physical and biological controls were included. After 21 days of incubation, $97.5 \%$ of the chromium was removed in the biotreatments, with an increase in $\mathrm{pH}$. This research demonstrated the importance of the interaction of biotic and abiotic factors to enhance the removal of chromium in acid waters from tanneries. The results are novel for the treatment of tanning effluents, reducing the concentration of trivalent chromium by a biological method that in turn increases the $\mathrm{pH}$, reaching permissible values and taking advantage of the own biodiversity of these effluents, benefits that make possible their later utility on a larger scale.

\section{INTRODUCCIÓN}

El vertimiento al ambiente de grandes cantidades de metales pesados se produce como consecuencia de diversas actividades industriales que provocan efectos negativos en el medio natural y en la salud humana. Entre dichos metales se encuentra el cromo, elemento químico de número atómico 24 , que posee cinco estados de oxidación, los cuales van desde $\mathrm{Cr}$ (II) a $\mathrm{Cr}$ (VI), siendo las formas trivalente y hexavalente las más estables (Fathima et al. 2012). En particular el Cr (VI) es altamente tóxico para todas las formas de vida, por su comprobada mutagenicidad y carcinogenicidad (Galvao y Corey 1987). Mientras que, el cromo (III) es un elemento esencial para la vida animal y humana, pero a concentraciones elevadas y bajo condiciones anóxicas llega a ser tóxico (Viti et al. 2003), al ser oxidado a Cr (VI); proceso que conduce a serias consecuencias ambientales. Esta oxidación está limitada por la capacidad oxidativa del oxígeno, los óxidos de manganeso, la concentración de cromo soluble en agua, el $\mathrm{pH}$, el área superficial disponible y las condiciones redox (Dhal et al. 2013).

El cromo trivalente es empleado en el proceso de curtido en las curtiembres, a partir del cual se generan residuos líquidos que deben ser tratados antes de su desecho final. Dicho tratamiento puede realizarse por métodos fisicos y químicos como intercambio iónico, ultrafiltración, osmosis inversa y precipitación química (Faouzi et al. 2013). Sin embargo, estas tecnologías son poco empleadas debido a la generación de subproductos contaminantes, poca efectividad a bajas concentraciones y elevados costos de operación y mantenimiento (Gómez-Bertel et al. 2008; Kanagaraj et al. 2013). Situación que se dificulta aún más al considerar que el sector curtidor en los países en desarrollo está representado principalmente por microempresas que tienen muy baja capacidad de inversión (Acosta et al. 2013, Benítez-Campo y Perafán 2016, Sanz et al. 2016).

Se plantea entonces, el uso de la biorremediación microbiana, en la que se aprovecha la capacidad de los microrganismos nativos y sus productos para el tratamiento natural de contaminantes como el cromo (Cañizares-Villanueva 2000). La tolerancia microbiana a los metales se basa en mecanismos relacionados con estructuras celulares o de resistencia específicos, que permiten regular los niveles intracelulares, mediante procesos de expulsión, atrapamiento intra y extracelular y reacciones de oxidorreducción, principalmente (Sharma et al. 2011, Fernández et al. 2018, Huang et al. 2018). Entre dichos mecanismos está la bioprecipitación, mediante la cual se forman complejos entre el metal y compuestos de sulfuro, carbonatos e hidróxidos (Cabrera 2005). Este proceso suele ser mediado por diferentes especies de bacterias, entre ellas, las bacterias reductoras de sulfato (BSR), las cuales forman sulfuros, con posterior precipitación de los metales presentes, provocando la separación final de estos (Vicente 2006, Madhavi et al. 2013).

De otro lado, Aravindhan et al. (2012), reportaron la extracción de cromo trivalente en solución a 100 ppm, mediante bioadsorción con Bacillus subtilis, obteniendo una remoción del $71.7 \%$ del metal, demostrando la importancia de materiales de soporte para la formación de biopelículas y su influencia en el proceso de descontaminación. Sin embargo, el grado de toxicidad, salinidad y acidez de los licores del curtido del cuero pueden afectar la capacidad de los microorganimos para remover el cromo (III) (Lefebvre y Moletta 2006).

Los estudios con BSR muestran bajos niveles de precipitación, por ejemplo, la adición de $900 \mathrm{~mL}$ de medio con $\mathrm{H}_{2} \mathrm{~S}$, subproducto del crecimiento de las BSR a una solución de 766 ppm de cromo (III), causó la precipitación de solamente el $13.1 \%$ del 
metal (Cabrera 2005). Otro estudio con biopelículas de BSR crecidas a $17 \mathrm{mg} / \mathrm{L}$ de cromo trivalente, mostró una precipitación del $58 \%$, pero cuando la concentración aumentó a 100 ppm, sólo se precipitó el $14 \%$ (Vicente 2006), resultados que demuestran la importancia de continuar con la búsqueda de métodos que permitan incrementar los porcentajes de precipitación de cromo. En este sentido, el objetivo del presente estudio fue evaluar la capacidad de remoción de cromo trivalente en aguas del curtido del cuero a partir de microorganismos acidófilos, nativos de aguas residuales de curtiembres, en biorreactores tipo lote.

\section{MATERIALES Y MÉTODOS}

\section{Muestreo}

El agua residual se tomó a la salida de los fulones de una curtiembre ubicada en la cabecera del municipio de Belén, Nariño (Colombia), en frascos de vidrio de $1 \mathrm{~L}$, previamente esterilizados y tratados con ácido nítrico al $10 \% \mathrm{v} / \mathrm{v}$. En el sitio de muestreo se midió la temperatura, $\mathrm{pH}$, salinidad y oxígeno disuelto. Las muestras se transportaron refrigeradas a $4{ }^{\circ} \mathrm{C}$ hasta el Laboratorio de Investigaciones Microbiológicas (LIM) del Departamento de Biología de la Universidad del Valle, para su respectivo procesamiento.

\section{Diseño de medios de cultivo para el aislamiento de microorganismos acidófilos de curtiembres}

Con el fin de realizar el aislamiento de microorganismos acidófilos resistentes a cromo trivalente, se diseñaron cinco medios de cultivo, tres de los cuales se prepararon con agua residual artificial (ARA) a concentraciones del $100 \%, 75 \%$ y $50 \%$ de las sales que componen el licor del curtido, según composición reportada por Ortega et al. (2001), denominados ARA1, ARA2 y ARA3, respectivamente. Teniendo en cuenta que ensayos previos mostraron la desnaturalización del agar al entrar en contacto con el ARA y la precipitación del cromo durante la esterilización por autoclave, fue necesario repartir en dos partes el volumen a preparar. Una parte, constituida por las sales del ARA, que se esterilizó por filtración con una membrana de 0.45 micras de tamaño de poro y la otra parte constituida por el agar, que se esterilizó con autoclave a $121^{\circ} \mathrm{C}$, durante $15 \mathrm{~min}$. Después de la esterilización se mezclaron rápidamente las dos partes, restituyéndose el volumen deseado.

El cuarto medio de cultivo, se preparó a partir de agua residual real (ARR) que se esterilizó por filtración y se solidificó con agar nutritivo. El último medio correspondió al medio 9K modificado (9Kmod) (Silverman y Lundgren 1959), la composición de los medios diseñados se detalla en el cuadro I. El pH de los medios se ajustó a $3.9 \pm 1$, con soluciones $1 \mathrm{~N}$ de

CUADRO I. COMPONENTES DE LOS MEDIOS DE CULTIVO DISEÑADOS

\begin{tabular}{|c|c|c|c|c|c|c|}
\hline \multirow{2}{*}{ Componentes } & \multirow{2}{*}{ unidades } & \multicolumn{5}{|c|}{ Medios de cultivo } \\
\hline & & ARA1 & ARA2 & ARA3 & ARR & 9Kmod \\
\hline Agar nutritivo & $\mathrm{g} / \mathrm{L}$ & & & & 23 & \\
\hline Agua del curtido & $\mathrm{mL} / \mathrm{L}$ & & & & 1000 & \\
\hline Agar bacteriológico & $\mathrm{g} / \mathrm{L}$ & 15 & 15 & 15 & & \\
\hline $\mathrm{NaHCO}_{3}$ & $\mathrm{~g} / \mathrm{L}$ & 2 & 1.5 & 1 & & \\
\hline $\mathrm{Cr}(\mathrm{OH}) \mathrm{SO}_{4}$ & $\mathrm{~g} / \mathrm{L}$ & 3 & 2.25 & 1.5 & & \\
\hline Extracto de carne & $\mathrm{g} / \mathrm{L}$ & 30 & 30 & 30 & & \\
\hline Formiato & $\mathrm{g} / \mathrm{L}$ & 2 & 1.5 & 1 & & \\
\hline Glucosa & $\mathrm{g} / \mathrm{L}$ & 10 & 10 & 10 & & 10 \\
\hline $\mathrm{NaCl}$ & $\mathrm{g} / \mathrm{L}$ & 15 & 11.25 & 7.5 & & \\
\hline$\left(\mathrm{NH}_{4}\right)_{2} \mathrm{SO}_{4}$ & $\mathrm{~g} / \mathrm{L}$ & & & & & 3 \\
\hline $\mathrm{Ca}\left(\mathrm{NO}_{3}\right)_{2}$ & $\mathrm{~g} / \mathrm{L}$ & & & & & 0.144 \\
\hline $\mathrm{Cr}(\mathrm{OH}) \mathrm{SO}_{4}$ & $\mathrm{~g} / \mathrm{L}$ & & & & & 2.25 \\
\hline $\mathrm{KCL}$ & $\mathrm{g} / \mathrm{L}$ & & & & & 0.1 \\
\hline $\mathrm{KH}_{2} \mathrm{PO}_{4}$ & $\mathrm{~g} / \mathrm{L}$ & & & & & 0.5 \\
\hline $\mathrm{MgSO} 4.7 \mathrm{H}_{2} \mathrm{O}$ & $\mathrm{g} / \mathrm{L}$ & & & & & 0.5 \\
\hline
\end{tabular}

ARA1 $=$ agua residual artificial al $100 \%$, ARA2 = agua residual artificial al $75 \%$, ARA3 $=$ agua residual artificial $50 \%$ ARR $=$ agua residual real, $9 \mathrm{Kmod}=9 \mathrm{~K}$ modificado 
$\mathrm{NaOH}$ o $\mathrm{HCl}$. Todos los medios fueron servidos en placas de Petri estériles y almacenados a $4{ }^{\circ} \mathrm{C}$ hasta el momento de su uso.

\section{Siembra y aislamiento de microorganismos en los medios de cultivo diseñados}

Para la siembra y aislamiento de los microorganismos se prepararon diluciones seriadas de las muestras de agua del curtido desde $10^{-1}$ a $10^{-3}$, utilizando agua peptonada al $0.1 \%$ como diluyente. Las siembras se realizaron por el método de recuento estándar en placa, mediante siembra en superficie (APHA 1998) y las placas se incubaron a $25^{\circ} \mathrm{C}$ por 7 días. Finalizado el período de incubación, se seleccionaron las placas que presentaban recuentos entre 30 y 300 colonias. Los recuentos fueron expresados en unidades formadoras de colonias por mililitro (UFC/mL). Debido a que las pruebas macro y microscópicas de todas las colonias crecidas en los medios de cultivo mostraron la presencia de levaduras, se tomó una colonia representativa de cada morfología presente en los diferentes medios y se sembraron en PDA y agar glucosado de Sabouraud para facilitar su diferenciación y evitar réplicas de la misma especie. En todos los medios de cultivo se observaron cuatro tipos de levaduras morfológicamente diferentes, se seleccionaron las más abundantes para conformar el inóculo de los bioensayos y en el momento del aislamiento se les asignaron los códigos LC1 A (levadura caja 1, cepa A) y LPH (levadura de pH ácido).

\section{Remoción de cromo trivalente de agua residual de curtiembres en ensayos tipo lote con matraces Erlenmeyer}

Los ensayos tipo lote se realizaron por triplicado en matraces de $500 \mathrm{~mL}$, los cuales fueron empacados con $170 \mathrm{~g}$ de arena de $2.5 \mathrm{a} 6.0 \mathrm{~mm}$ de grosor, previamente lavada y esterilizada, empleada como lecho de soporte. Los matraces fueron cargados con $300 \mathrm{~mL}$ de agua residual del curtido de pieles, diluida a $1021 \mathrm{mg} / \mathrm{L}$ de cromo trivalente, esterilizada por filtración. Posteriormente, se agregó a los matraces el inóculo resultante de centrifugar $90 \mathrm{~mL}$ de un cultivo de $48 \mathrm{~h}$, crecido en medio TGEA (agar triptona glucosa extracto de levadura), compuesto por las cepas LC1A y LPH, a una concentración de 2 a $5 \times 10^{8} \mathrm{cel} / \mathrm{mL}$, para cada cepa. Se incluyeron tres testigos, uno de tipo físico que careció de inóculo microbiano, para determinar si la arena tenía influencia en la remoción de cromo, el segundo testigo de tipo químico, que careció de inóculo microbiano y de lecho de soporte, para determinar los efectos de matriz que pudieran provocar la mineralización del cromo y el tercer testigo, denotado como el testigo biológico, sin lecho de soporte, para establecer el efecto de los microorganismos en la remoción del metal. Todos los matraces permanecieron estáticos sobre una mesa del laboratorio, a temperatura ambiente (entre 20 a $25^{\circ} \mathrm{C}$ ), durante 21días. Al final del período de incubación se realizaron siembras por el método de recuento estándar en placa en agar Sabouraud, para determinar la viabilidad de las levaduras que componían el consorcio y la esterilidad de los testigos físico y químico.

La determinación del cromo trivalente se realizó tres veces por semana, tomando $2 \mathrm{~mL}$ de cada uno de los matraces, teniendo cuidado de no causar disturbios en su contenido. La concentración del cromo trivalente se midió por el método colorimétrico empleando un espectrofotómetro UV-visible, marca Thermo-Scientific Genesys-10S a una longitud de onda de $576 \mathrm{~nm}$, de acuerdo con el método validado por espectrometría de absorción atómica de flama (FAAS) realizado por Escalera et al. (2006). Para el análisis se determinaron espectros de absorbancia en el rango UV-visible (200-800 mm), obtenidos a partir de soluciones patrón preparadas con los insumos químicos empleados en las curtiembres de Belén. Se comprobó que no hubo presencia de Cr(VI) mediante determinaciones periódicas realizadas por espectrofotometría simultánea de Cr (III) y Cr (VI), por regresión lineal multivariante (RLM), según procedimiento estandarizado por Saavedra (2017).

\section{Caracterización morfológica, bioquímica y mole- cular de los aislados microbianos}

Se describieron las características macroscópicas de las colonias: forma, tamaño, elevación, borde y topografía, al igual que características microscópicas: forma celular y tipo de agrupación. Al observar que un mismo microorganismo formaba colonias diferentes en respuesta a los medios de cultivo diseñados, se realizó una prueba de pleomorfismo con las cepas seleccionadas para el inóculo. La prueba consistió en verificar macroscópicamente las características desarrolladas por las cepas en respuesta al medio de cultivo, para esto cada una se sembró por separado, en los diferentes medios de cultivo y se analizaron las diferencias morfológicas tras siete días de incubación a $25^{\circ} \mathrm{C}$.

La caracterización bioquímica se realizó para todos los aislados y consistió en pruebas de asimilación de los azúcares: glucosa, xilosa, arabinosa, manosa, maltosa y lactosa con rojo de fenol como indicador de $\mathrm{pH}$. Las pruebas se consideraron positivas por el cambio de coloración de naranja-rojizo a amarillo. Adicionalmente se realizó una prueba 
de formación de tubo germinal en suero sanguíneo para descartar o confirmar la presencia de Candida albicans.

Para la caracterización molecular se hizo extracción de ADN a partir de cultivos puros de las cepas de levaduras seleccionadas, usando el paquete Ultra-Clean ${ }^{\circledR}$ Microbial DNA Isolation, (Mo Bio laboratorios, Inc.). Se realizó la amplificación de las regiones ribosomales de espaciadores transcritos internos (ITS, por sus siglas en inglés) mediante el uso de los cebadores ITS1 (5'TCCGTAGGTGAACCTGCGG3') e ITS4 (5'TCCTCCGCTTATTGATATGC $\left.3^{\prime}\right)$, los cuales se anclan en los ADNr $18 \mathrm{~S}$ y $28 \mathrm{~S}$, respectivamente. El coctel de PCR preparado para la amplificación contenía: $0.4 \mathrm{mM}$ de cada cebador, 0.2 $\mathrm{mM}$ de DNTPs, $1.75 \mathrm{mM}$ de $\mathrm{MgCl}_{2}$, amortiguador fosfato a $1 \mathrm{X}, 0.1 \mu \mathrm{L}$ de Taq polimerasa y $5 \mu \mathrm{L}$ de ADN para un volumen final de $50 \mu \mathrm{L}$. La amplificación se realizó en un termociclador Veriti (Applied Biosystems) y las condiciones finales de PCR fueron: desnaturalización inicial a $94{ }^{\circ} \mathrm{C}$ por 5 min, seguido de 35 ciclos de $94^{\circ} \mathrm{C}$ por $30 \mathrm{~s}$ cada uno a $48{ }^{\circ} \mathrm{C}$ por $30 \mathrm{~s}, 72{ }^{\circ} \mathrm{C}$ por $90 \mathrm{~s}$ y una etapa de elongación a $72{ }^{\circ} \mathrm{C}$ por $5 \mathrm{~min}$.

Posteriormente, se realizó la secuenciación de los amplificados a través de los servicios de la compañía Macrogen Corp. EUA. Las secuencias parciales de ADNr fueron editadas con el programa Chromas Lite, versión 2.1. Las secuencias obtenidas fueron comparadas con las secuencias de levaduras disponibles en la base de datos BLAST del Centro Nacional para la Información en Biotecnología (NCBI, por sus siglas en inglés) y los números de acceso fueron MH732908 y MH732909 para Yarrowia lipolytica y Candida fluviatilis, respectivamente.

\section{Análisis estadísticos}

Se comparó el desempeño de los medios de cultivo diseñados en la recuperación microbiana, cuya variable de respuesta correspondió al número de UFC/mL. La comparación de las medias se realizó mediante un análisis de varianza de un factor, con un nivel de significancia de $\mathrm{p}<0.05$.

La eficiencia de remoción de cromo en los matraces se evaluó mediante un modelo lineal mixto, cuya variable de respuesta fue la remoción de cromo trivalente en el tiempo, en el cual se compararon los efectos fijos del reactor y del tiempo, incluyendo en cada caso sus efectos aleatorios. Al encontrar que hubo diferencias significativas en la comparación anterior, se efectuó la prueba de Tukey para determinar el mejor tratamiento. Todos los análisis se realizaron con el programa R, versión 6.0 (R Core Team 2014).

\section{RESULTADOS Y DISCUSIÓN}

\section{Caracterización del agua residual}

Los resultados de la caracterización física y química del agua residual del curtido mostraron una elevada concentración de cromo y un $\mathrm{pH}$ ácido en la muestra (Cuadro II), ambos parámetros están por fuera del valor límite máximo permitido en vertimientos de aguas residuales, según la Resolución 0631 de 2015 (MADS 2015), lo que revela la necesidad de emplear medidas adecuadas para disminuir el impacto de los desechos descargados al ambiente. Estos resultados son consistentes con los encontrados por Sepehr et al. (2012) y Ramírez y Benítez-Campo (2013), lo que pone en evidencia las condiciones tóxicas de selectividad a las que están sometidos los microorganismos que habitan estos ambientes. Por lo tanto, se revela la importancia de seleccionar microorganismos autóctonos adaptados a estos niveles de contaminación para llevar a cabo procesos de biorremediación.

CUADRO II. ANÁLISIS FÍSICOS Y QUÍMICOS DELAGUA RESIDUAL DE CURTIEMBRE

\begin{tabular}{lcc}
\hline Parámetro & Resultado & VLMP* \\
\hline Temperatura $\left({ }^{\circ} \mathrm{C}\right)$ & 20 & $<40$ \\
pH (unidades) & 4.04 & $6-9$ \\
Salinidad $(\mathrm{psu})$ & 40.89 & - \\
Cromo total $(\mathrm{mg} / \mathrm{L})$ & 5021 & 1.5 \\
Oxígeno disuelto $\left(\mathrm{mg} \mathrm{O}_{2} / \mathrm{L}\right)$ & 4.15 & - \\
\hline
\end{tabular}

*Valor Límite Máximo Permisible para vertimientos de aguas residuales no domésticas a cuerpos de aguas superficiales y a los sistemas de alcantarillado público, para fabricación de artículos de piel, curtido y adobo de pieles (MADS 2015)

\section{Aislamiento de microorganismos acidófilos en los medios de cultivo diseñados}

Los medios de cultivo diseñados permitieron el aislamiento de cuatro tipos de levaduras diferentes, sin evidencia de crecimiento bacteriano, las cuales se designaron como: LC1A, LPH, D3 y D4. Los conteos totales fueron muy similares, encontrándose en un orden de magnitud de $10^{3} \mathrm{UFC} / \mathrm{mL}$ (Fig. 1). El análisis estadístico corroboró que no hubo diferencias significativas $(\mathrm{p}=3.78)$, en la capacidad de recuperación microbiana por parte de los medios probados. Pese a la similitud en los recuentos totales, se observó una mayor abundancia de las cepas LC1A y LPH, en una proporción de $5: 1$, con respecto a las otras levaduras, por lo cual fueron seleccionadas para los biotratamientos. 


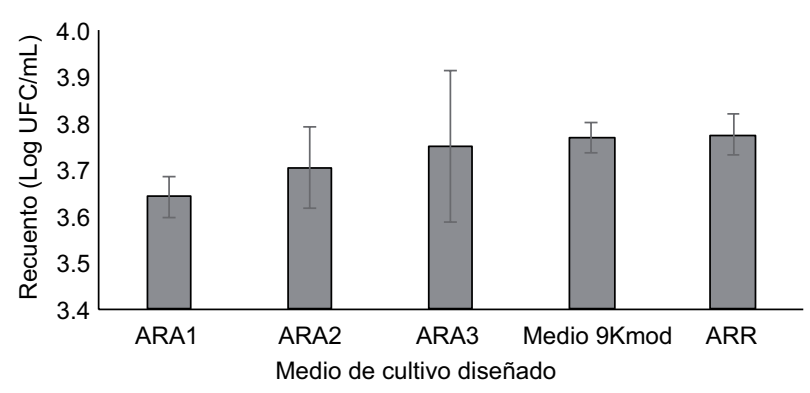

Fig. 1. Recuento en placa para los diferentes medios de cultivo evaluados. Las barras de error representan la desviación estándar a partir de los experimentos realizados por triplicado

Considerando que se encontraron cambios morfológicos sustanciales en respuesta al medio de cultivo, se confirmó este comportamiento para las cepas LC1A y LPH, las cuales presentaron colonias más grandes en los medios ARR y ARA1. Ambas levaduras formaron colonias pubescentes, con bordes filamentosos más pronunciados, en el medio ARR, mientras que en los medios 9Kmod y ARA3 presentaron bordes glabros (Fig. 2).

A pesar de la capacidad de ciertas bacterias para crecer en medios hostiles, no hubo crecimiento de estos microorganismos en los medios diseñados, sino que se favoreció la prevalencia de levaduras; resultados que pueden explicarse por las condiciones de selectividad de los medios evaluados, así como por la salinidad, el $\mathrm{pH}$ y el cromo trivalente. Se ha documentado que la salinidad ocasiona plasmólisis en microorganismos no adaptados (Reid et al. 2006) y la inhibición de rutas de asimilación de glucosa en aerobios (Bruzual y Ochoa-Herrera 2014), lo que pone en evidencia la toxicidad del cromo. Una estrategia importante para resistir la salinidad se ha estudiado ampliamente en bacterias halófilas y halotolerantes, las que contrarrestan los efectos de la presión osmótica mediante la acumulación citoplasmática de solutos compatibles, que incluyen la síntesis de osmolitos orgánicos y/o la inclusión de iones inorgánicos como $\mathrm{Na}^{+}$y K ${ }^{+}$, que mantienen la presión de turgencia sin presentar toxicidad (Roberts 2005).

Por otro lado, aunque el medio 9Kmod, no poseía $\mathrm{NaCl}$ entre sus componentes, también inhibió el crecimiento bacteriano, mostrando que no solamente la salinidad limitó su crecimiento, sino también el pH ácido, al igual que en los otros medios de cultivo. Okeke (2008) y Chandra y Singh (2014) aislaron bacterias capaces de sobrevivir a altas concentraciones de salinidad y acidez, sin causar su inhibición, pero en este caso, la diferencia estuvo en la alta concentración de cromo en el agua residual, que pudo ser un tercer factor de inhibición. Esto es consistente con lo encontrado por Bruzual y Ochoa-Herrera (2014) quienes observaron que el cromo trivalente, a concentraciones superiores a $100 \mathrm{mg} / \mathrm{L}$ causó inhibición de bacterias fermentadoras de glucosa.

En este sentido, Fathima et al. (2012) lograron el aislamiento de cepas de Bacillus sp., en caldo nutritivo a $\mathrm{pH}$ neutro, suplementado con $100 \mathrm{mg} / \mathrm{L}$ de sulfato de cromo, condiciones de cultivo que favorecieron el crecimiento de bacterias, características que difieren ampliamente de las condiciones físicas y químicas propias de las aguas del curtido (Ramírez y Benítez 2013). De esta manera, se evidencia que la sumatoria de salinidad, acidez y contenido de cromo trivalente presentes en los medios de cultivo, ejercen una fuerte selección en el crecimiento de los

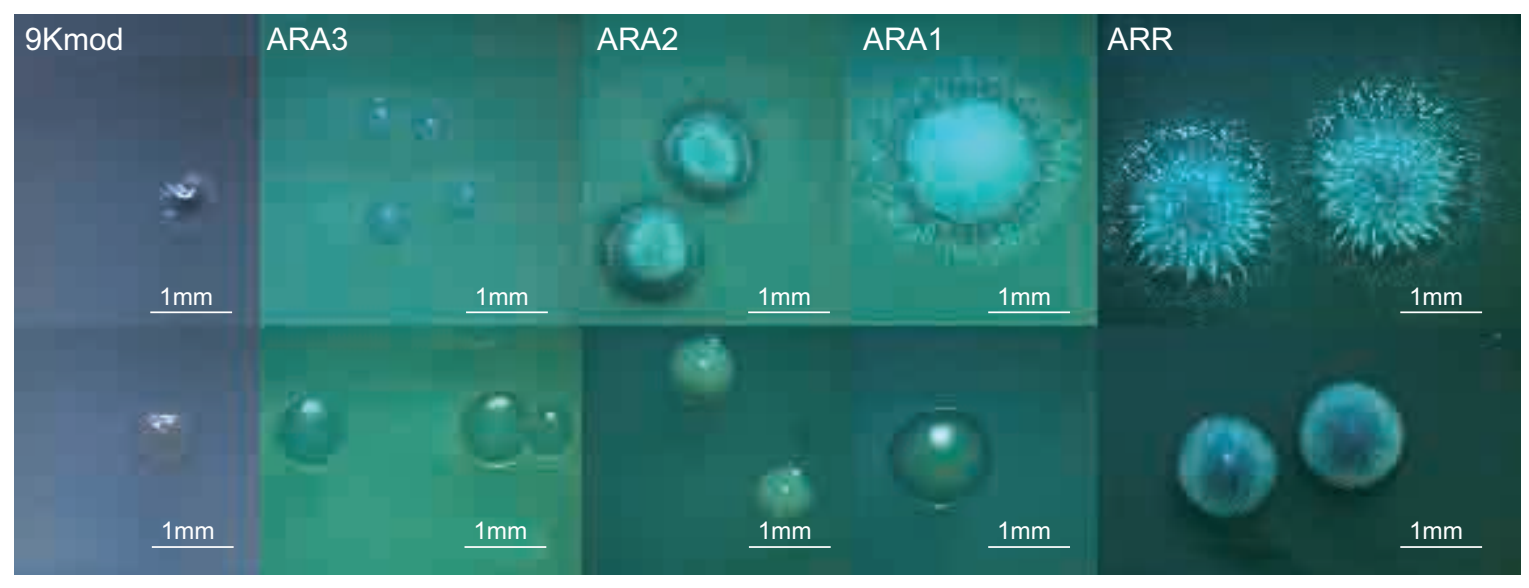

Fig. 2. Pleomorfismo en respuesta al medio de cultivo. La fila superior corresponde a la cepa LPH y la fila inferior a LC1A. Nótese que el borde y el tamaño son más pronunciados en los medios ARA1 y ARR 
microorganismos, favoreciendo en este caso a las levaduras, que encontraron en estos medios de cultivo condiciones más adecuadas para su crecimiento que las bacterias, y por lo tanto, son microorganismos con habilidades interesantes para el tratamiento de efluentes propios del curtido de pieles.

En cuanto al pleomorfismo observado en las levaduras aisladas, se sabe que las condiciones del medio de cultivo tienen una fuerte influencia en la expresión de cambios morfológicos en levaduras, como el caso de Candida albicans, donde los blastoconidios, tubos germinativos, pseudohifas e hifas verdaderas corresponden a adaptaciones a la explotación máxima de los nutrientes presentes en los sustratos empleados para su crecimiento (Danhof y Lorenz 2015). Por otra parte, en bacterias como Bacillus subtilis y Bacillus cereus expuestas a cromo trivalente se ha observado polimorfismo marcado por aumento o disminución del tamaño, con cambios en la superficie celular, debidos a situaciones de estrés en respuesta a la carga de contaminantes (Sundar et al. 2002, Moreno et al. 2019). Esta variación fenotípica es consecuencia de la diversidad de mecanismos dinámicos que generan polimorfismo genético. En levaduras dichos mecanismos se han identificado en polimorfismos nucleotídicos simples, inserciones o delecciones de secuencias cortas, recombinación y conversión de genes, duplicación de genes, rearreglos cromosómicos, hibridación interespecífica y cambios de ploidia, principalmente (Guillamon y Barrio 2017).

\section{Evaluación de la remoción de cromo trivalente en agua residual del curtido de pieles}

La remoción de cromo trivalente en el biotratamiento fue significativamente mayor a los testigos $(\mathrm{p}=1 \mathrm{e}-05)$ (Cuadro III) y se realizó de manera

\section{CUADRO III. PRUEBAS POST-HOC ANDEVA TUKEY}

\begin{tabular}{lccrc}
\hline $\begin{array}{l}\text { Post } \\
\text { ANOVA }\end{array}$ & $\begin{array}{c}\text { Estimate } \\
\text { Std. }\end{array}$ & Error & $\begin{array}{c}\mathrm{z} \\
\text { value }\end{array}$ & $\begin{array}{c}\mathrm{Pr} \\
(>|\mathrm{z}|)\end{array}$ \\
\hline $2-1==0$ & 500.66 & 34.28 & 14.605 & $<1 \mathrm{e}-05^{*}$ \\
$3-1==0$ & 190.27 & 34.28 & 5.550 & $<1 \mathrm{e}-05^{*}$ \\
$4-1==0$ & -16.30 & 34.28 & -4.851 & $<1 \mathrm{e}-05^{*}$ \\
$3-2==0$ & -310.39 & 34.28 & -9.055 & $<1 \mathrm{e}-05^{*}$ \\
$4-2==0$ & -666.96 & 34.28 & -19.456 & $<1 \mathrm{e}-05^{*}$ \\
$4-3==0$ & -356.57 & 34.28 & -10.402 & $<1 \mathrm{e}-05^{*}$ \\
\hline
\end{tabular}

Los números 1, 2, 3 y 4, corresponden a: testigo físico, testigo químico, testigo biológico y biotratamiento respectivamente. El (*) indica diferencias significativas en cada comparación. exponencial, alcanzando el $65 \%$ durante los primeros cinco días, con una velocidad de $13 \mathrm{mg} \mathrm{Cr}$ (III)/L/h, remoción que fue aumentando hasta alcanzar el $97.5 \%$, a los 21 días (Fig. 3). Por su parte, el testigo físico mostró una remoción del $52 \%$, con una velocidad de $10.4 \mathrm{mg} \mathrm{Cr}(\mathrm{III}) / \mathrm{L} / \mathrm{h}$ durante el mismo período de tiempo, alcanzando una remoción del $73 \%$ al final del experimento, indicando que la arena influyó fuertemente en la captura del metal. Es importante destacar el comportamiento del testigo biológico, inóculo microbiano sin lecho de soporte que, aunque presentó una fase de latencia durante los primeros cinco días, logró recuperarse hasta superar levemente el desempeño del testigo físico, con un $75 \%$ de remoción hacia el final del experimento, encontrándose aún en la fase exponencial, periodo de mayor actividad metabólica, lo que favoreció la bioprecipitación, bioadsorción o bioacumulación del metal.

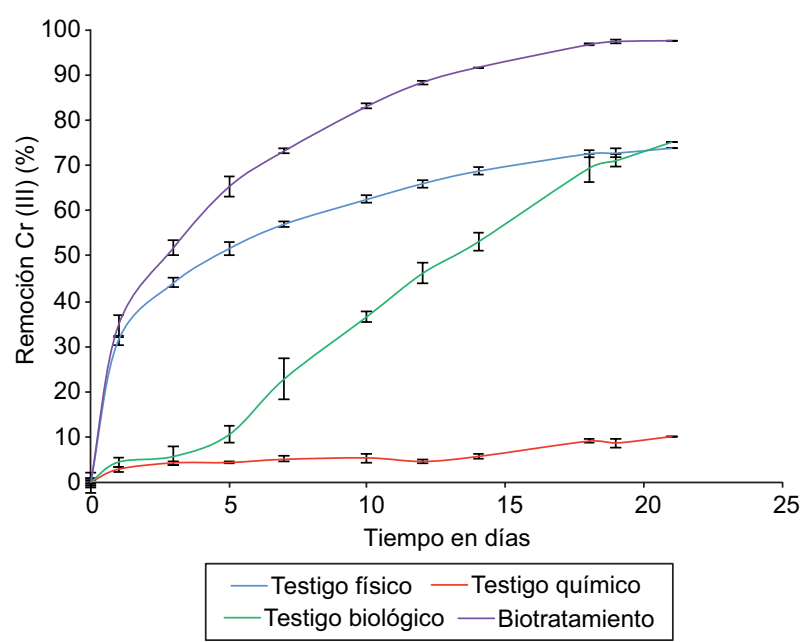

Fig. 3. Remoción de cromo trivalente a través del tiempo para una concentración inicial de $1021 \mathrm{mg} / \mathrm{L}$. Las barras de error representan la desviación estándar de los ensayos realizados por triplicado

Por otro lado, el testigo químico mostró una remoción mínima, cercana al $10 \%$. Este comportamiento indica que el proceso de remoción del metal ocurrió de forma mixta, gracias a un componente abiótico (físico y químico), basado en la adsorción de $\mathrm{Cr}$ (III), realizado por la arena y a un componente biológico, que permitió la bioprecipitación y bioadsorción del $\mathrm{Cr}$ (III) por parte de las levaduras.

Fue evidente el cambio del $\mathrm{pH}$ en los tratamientos donde se encontraba el consorcio (Fig. 4), observándose un aumento de 1.24 unidades en el biotratamiento y de 0.43 unidades en el testigo biológico. Mientras 
que en el testigo físico se observó un ligero aumento el primer día, pero fue disminuyendo paulatinamente hasta alcanzar el valor inicial. Caso contrario ocurrió con el testigo químico, donde el $\mathrm{pH}$ disminuyó en 0.2 unidades, en los 21 días de incubación.

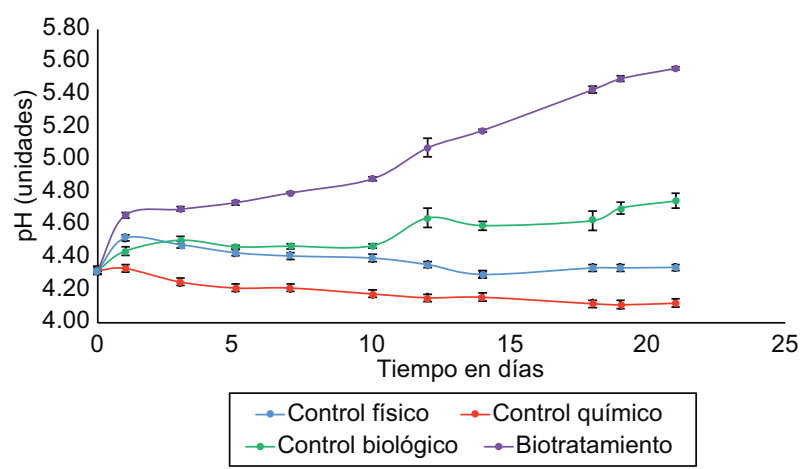

Fig. 4. Variación del $\mathrm{pH}$ en los tratamientos a través del tiempo

Los resultados demuestran la influencia del inóculo microbiano en la remoción del metal, que fue favorecida por las características del lecho de soporte, mediante el cual, los factores físicos y bioquímicos confluyeron para aumentar la eficiencia de remoción en el biotratamiento, así como el aumento del pH. Este incremento se relaciona directamente con la solubilidad del Cr (III) y con el aumento de la afinidad del metal por los grupos $\mathrm{OH}$, facilitando la formación de especies de $\mathrm{Cr}(\mathrm{OH})_{2}{ }^{+}$, que han demostrado una mayor capacidad de adsorción (Leyva et al. 2000), para la que se establece un rango de formación a $\mathrm{pH}$ entre 5.4 y 8.4 (Avudainayagam 2003), adicionalmente, a $\mathrm{pH}>$ a 5 , también se forma $\mathrm{Cr}(\mathrm{OH})_{3}$ que es la especie de cromo más precipitante (Yun et al. 2001).

El aumento del $\mathrm{pH}$ alcanzado por el biotratamiento y el testigo biológico, responde a la excreción de metabolitos no identificados, entre los que podría estar el amoniaco, resultado de la utilización de aminoácidos como fuente de carbono en ausencia de glucosa (Palková et al. 1997). Se ha propuesto un modelo de alcalinización generalizado para hongos en el que los aminoácidos metabolizados ingresan al interior celular, a través de transportadores transmembranales, facilitados por un factor de transcripción (Stp2p). Una vez dentro los aminoácidos son convertidos a ácidos tricarboxilicos intermediarios del ciclo de Krebs, a través de varias rutas; muchas de estas requieren la producción de acetil-CoA y el transporte intracelular mediado por la acetil-CoA hidrolasa (Ach1p). Todos estos eliminan los grupos amino, donde el exceso de nitrógeno es excretado en forma de amoniaco y $\mathrm{CO}_{2}$, lo que produce la alcalinización del medio (Vylkova et al. 2011).

La figura 5, muestra el estado inicial y final de los diferentes matraces, donde se observa el cambio de coloración experimentado durante el tiempo. El testigo físico demostró que la arena tuvo una fuerte influencia en el proceso de remoción del cromo, al observarse la columna de agua de color azul translúcido (Fig. 5a) en comparación con el testigo químico (Fig. 5b), que presentó turbidez. Este resultado es consistente con lo encontrado por Khamis et al. (2009) quienes reconocen la capacidad de los silicatos presentes en la arena para ejercer procesos de remoción de cromo, entre los que se destacan la protonación y de-protonación del metal. Fendorf et al. (1994) y Fendorf y Sparks (1994) citados por Avudainayagam (2003), estudiaron el mecanismo de adsorción de $\mathrm{Cr}$ (III) sobre sílice, usando espectroscopia de estructura fina de absorción extendida y encontraron que el $\mathrm{Cr}$ (III) forma complejos superficiales monodentados sobre sílice (es decir, un único punto de unión entre el ligando y el metal). Característica favorecida por el área superficial de la arena debido a su porosidad y gran contenido de sitios de intercambio iónico (Awan et al. 2003, Loarte y Sanabria 2015).

La coloración translúcida de la columna de agua y el precipitado abundante de color blanco azuloso que presenta el testigo biológico (Fig. 5d), indican que hubo una acción sólo de tipo biológico, bien sea

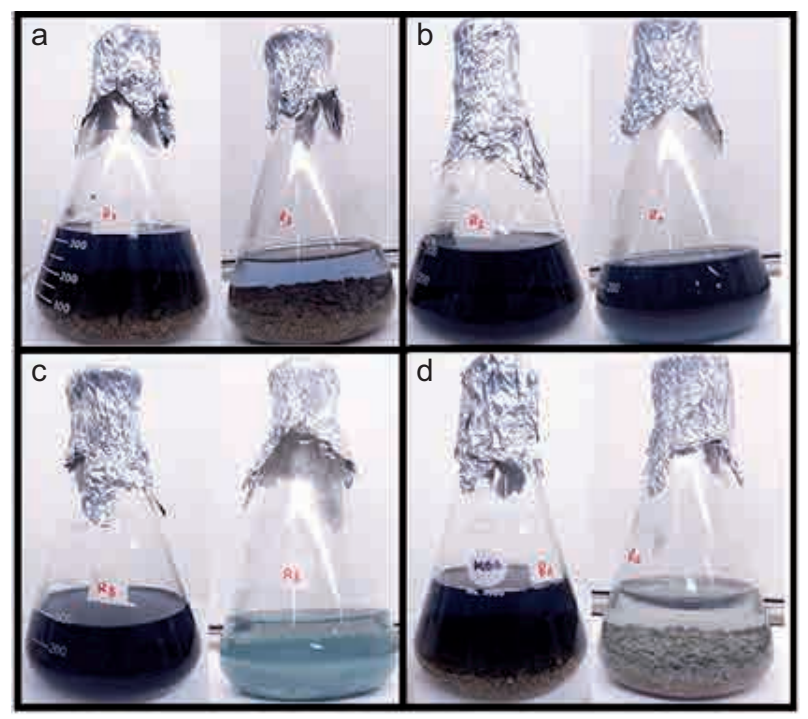

Fig. 5. Estado inicial (izquierda) y final (derecha) de los tratamientos realizados. a) testigo físico, b) testigo químico, c) testigo biológico, d) biotratamiento 
por bioprecipitación, bioadsorción o bioacumulación celular. La bioacumulación de Cr (III) ha sido demostrada para hongos de Paecilomyces lilacinus en efluentes de curtiembres (Sharma y Adholeya 2011). Por su parte la bioprecipitación de cromo trivalente fue propuesta por Gómez-Bertel et al. (2008) para P. chrysosporium.

En el biotratamiento (Fig. 5d) la coloración de la columna de agua es mucho más translúcida, con un precipitado azuloso en la superficie de la arena, indicando que el cromo se ha precipitado junto con la biomasa resultante, depositada sobre la arena, evidenciándose la relación biótica-abiótica que redunda en una mayor eficiencia.

\section{Caracterización de los aislados microbianos}

Las pruebas de asimilación de azúcares por parte de los aislados microbianos mostraron en común la asimilación de glucosa y manosa (Cuadro IV), considerándose positivas por el cambio de coloración de naranja rojizo a amarillo. Dependiendo del microorganismo y el carbohidrato empleado, se apreció un cambio de coloración para la reacción negativa, virando de color naranja rojizo inicial, a un rojo cereza intenso, que indica la alcalinización del medio de cultivo. Respecto a la identificación molecular el análisis realizado en BLAST a las cepas seleccionadas LC1A y LPH, permitió identificarlas como Yarrowia lypolitica y Candida fluviatilis con una identidad de $100 \%$ y $99 \%$, respectivamente. Los números de acceso en el Genbank fueron MH732908 para Y. lipolytica LC1A y MH732909 para C. fluviatilis LPH.

Los resultados logrados con la asociación de $Y$. lypolitica y C. fluviatilis son muy promisorios y de alto impacto para la industria del cuero, toda vez que al ser comparados con otros estudios, se destaca la eficiencia de remoción obtenida a la elevada concentración de cromo evaluada (1021 mg/L). Sundar et al (2002) reportan la eliminación del $98 \%$ del cromo (III) con Bacillus subtilis y Bacillus cereus, en un reactor de flujo continuo, a concentraciones máximas de $340 \mathrm{mg} / \mathrm{L}$ del metal, para agua residual diluida 1:10, valores mucho menores a los de este estudio.

De igual manera, Fathima et al. (2012) emplearon el consorcio de Bacillus subtilis VITSCCr01 y Bacillus cereus VITSCCr02, en aguas residuales sintéticas de tenerías que contenían 1000 ppm de $\mathrm{Cr}$ (III), $\mathrm{pH}$ entre 3.5 y 4 , y caolinita como medio de soporte, logrando una remoción de cromo del $99.8 \%$ tras cuatro ciclos de tratamiento; mientras que en

CUADRO IV. DESCRIPCIÓN MORFOLÓGICA DE LOS AISLADOS MICROBIANOS (LC1A, LPH, D3 y D4) EN AGAR SABOURAUD Y ASIMILACIÓN DE AZÚCARES EN CALDO ROJO DE FENOL

\begin{tabular}{lcccc}
\hline Características & \multicolumn{4}{c}{ Microorganismo } \\
\cline { 2 - 5 } & LC1A & LPH & D3 & D4 \\
\hline Morfología celular & Ovaladas & Ovaladas & Ovaladas & Ovaladas \\
Morfología de las colonias & & & & \\
Forma & Circular & Circular & Circular & Circular \\
Borde & Filamentoso & Entero & Entero & Ondulado \\
Elevación & Convexa & Convexa & Cóncava & Plana \\
Superficie & Rugosa & Lisa & Lisa & Lisa \\
Color & Blanca & Crema & Crema & Blanca \\
Tubo germinal & Negativo & Negativo & Negativo & Negativo \\
Hidrólisis de urea & Negativo & Negativo & Negativo & Negativo \\
Asimilación de: & & & & \\
Glucosa & + & + & + & + \\
Xilosa & $-/ \mathrm{R}$ & $-/ \mathrm{R}$ & - & - \\
Arabinosa & $-/ \mathrm{R}$ & $-/ \mathrm{R}$ & - & - \\
Manosa & + & + & + & + \\
Maltosa & - & + & + & - \\
Lactosa & $-/ \mathrm{R}$ & - & - & - \\
Identificación & Candida & Yarrowia & NI & NI \\
& fluviatilis & lipolytica & & \\
\hline
\end{tabular}

$\mathrm{R}=$ cambio de coloración a rojo intenso, $\mathrm{NI}=$ no identificada 
el presente estudio se alcanzó una remoción del $97.5 \%$ en un solo ciclo y con agua residual real de curtiembre donde las condiciones físicas y químicas son muy diferentes a las del agua residual sintética, carente de diversos factores que pueden afectar el funcionamiento del proceso de remoción del cromo. Pellón et al. (2011) emplearon el alga Scenedesmus obliquus inmovilizada sobre espuma de poliuretano con densidad de $45 \mathrm{~kg} / \mathrm{m}^{3}$, en un reactor biológico que alcanzó una remoción del $92.4 \%$ a una concentración de solamente $85.6 \mathrm{mg} / \mathrm{L}$ de cromo.

En cuanto a la capacidad biorremediadora de las levaduras utilizadas, Yarrowia lipolytica ha sido reportada en la degradación de hidrocarburos aromáticos y alifáticos, descomposición de 2,4,6-trinitrotolueno y biorremediación de metales pesados como níquel, cobre y cromo (Shinde et al. 2012). Para cromo, los estudios han sido enfocados principalmente hacia el estado hexavalente, ya sea en su reducción (Rao et al. 2013) o en su adsorción (Bankar et al. 2009). En cuanto a Candida fluviatilis, no se encontraron reportes que la vinculen en procesos de biorremediación, por lo tanto, este trabajo representa el primer reporte de Y. lipolitica LC1A y C. fluviatilis LPH, como microorganismos eficientes en la remoción de cromo trivalente presente en aguas residuales de curtiembres.

\section{CONCLUSIONES}

Se demostró la viabilidad y eficiencia de un biotratamiento empacado con arena como lecho de soporte y de la asociación de $Y$. lipolitica LC1A y $C$. fluviatilis LPH para la remoción de cromo trivalente en agua residual real del curtido, con aumento del $\mathrm{pH}$, lo que permite aproximarse a los valores permitidos para el vertimiento de las aguas residuales de curtiembres. Este sistema biótico abiótico puede ser escalado para la biodepuración de efluentes de curtiembres, debido a su alta eficiencia y fácil operatividad, lo que redundará en bajos costos de operación y mantenimiento en las industrias curtidoras que no poseen métodos asequibles para el tratamiento de este tipo de efluentes.

\section{AGRADECIMIENTOS}

A la Universidad del Valle por el apoyo financiero y logístico, al estadístico Wilmar Torres y al químico Jorge Iván Saavedra por su asesoría durante el desarrollo de esta investigación.

\section{REFERENCIAS}

Acosta G.E., Coy C.A., Bourdon A. y Cuervo E. (2013). La electrocoagulación como un tratamiento eficiente para la remoción de metales pesados presentes en aguas residuales. Revista Facultad de Ciencias Básicas 9 (2), 306-317. DOI: $10.18359 / \mathrm{rfcb} .389$

APHA (1998). Standard methods for the examination of water and wastewater. 20a ed. American Public Health Association. Washington, EUA, 1325 pp.

Aravindhan R., Fathima A., Selvamurugan M., Rao J.R. y Balachandran U.N. (2012). Adsorption, desorption, and kinetic study on $\mathrm{Cr}$ (III) removal from aqueous solution using Bacillus subtilis biomass. Clean. Technol. Envir. 14 (4), 727-735.

DOI: $10.1007 / \mathrm{s} 10098-011-0440-7$

Avudainayagam S., Megharaj M., Owens G., Kookana R.S., Chittleborough D. y Naidu R. (2003). Chemistry of chromium in soils with emphasis on tannery waste sites. In. Rev. Environ. Contam. Toxicol. 178, 53-91. DOI: 10.1007/0-387-21728-2_3

Awan M.A., Qazi I.A. y Khalid I. (2003). Removal of heavy metals through adsorption using sand. J. Environment. Sci.15 (3), 413-416.

Bankar A.V., Kumar A.R. y Zinjarde S.S. (2009). Removal of chromium (VI) ions from aqueous solution by adsorption onto two marine isolates of Yarrowia lipolytica. J. Hazard. Mater. 170 (1), 487-494.

DOI: 10.1016/j.jhazmat.2009.04.070

Benítez-Campo N. y Perafán-Cabrera A. (2016). Tanneries of El Cerrito (Valle del Cauca): A Look about your environmental and socioeconomic reality. Rev. UDCA. Act. Div. Cient. 19 (2), 457-66.

Bruzual A.B. y Ochoa-Herrera V. (2014). Efecto inhibitorio de cromo, cloruro y sulfuro en bacterias aeróbicas degradadoras de glucosa. Tesis de Licenciatura, Facultad de Ciencias e Ingeniería, Universidad San Francisco de Quito. Quito, Ecuador, 98 pp.

Cabrera R.G. (2005). Precipitación de iones metálicos contaminantes mediante bacterias azufre-oxidantes y sulfato-reductoras. Tesis de Doctorado. Facultad de Ciencias, Universidad de Cádiz. Cádiz, España, 235 pp.

Cañizares-Villanueva R.O. (2000). Biosorción de metales pesados mediante el uso de biomasa microbiana. Rev. Latinoam. Microbiol. 42 (3), 131-143.

Chandra P. y Singh D.P. (2014). Removal of Cr (VI) by a halotolerant bacterium Halomonas sp. CSB 5 isolated from sāmbhar Salt Lake Rajastha (India). Cell. Mol. Biol. 60 (5), 64-72. DOI: $10.14715 / \mathrm{cmb} / 2014.60 .5 .12$

Danhof H.A. y Lorenz M.C. (2015). The Candida albicans ATO gene family promotes neutralization of the macrophage phagolysosome. Infect. Immun. 83 (11), 4416-4426. DOI: 10.1128/IAI.00984-15. 
Dhal B., Thatoi H.N., Das N.N. y Pandey B.D. (2013). Chemical and microbial remediation of hexavalent chromium from contaminated soil and mining/metallurgical solid waste: A Review. J. Hazard. Mater. 250. 272-291. DOI: 10.1016/j.jhazmat.2013.01.048.

Escalera C.R., Arteaga L., Baldivieso A. y Vega R. (2006). Desarrollo y validación de un método espectrofotómetrico/colorimétrico para la determinación de cromo (III) en licores residuales de piquelado-curtido. Universidad Privada Boliviana-Investigación y Desarrollo 6, 95-104.

Faouzi M., Merzouki M. y Benlemlih M. (2013). Contribution to optimize the biological treatment of synthetic tannery effluent by the sequencing batch reactor. J. Mater. Environ. Sci. 4 (4), 532-41.

Fathima A., Rao J. R. y Nair B.U. (2012). Trivalent chromium removal from tannery effluent using kaolinsupported bacterial biofilm of Bacillus sp. isolated from chromium polluted soil. J. Chem. Technol. Biot. 87 (2), 271-279. DOI: 10.1002/jctb.2710.

Fernández P.M., Viñarta S.C., Bernal A.R., Cruz E.L. y Figureoa L. (2018). Bioremediation strategies for chromium removal: Current research scale-up approach and future perspectives. Chemosphere 208 139-148. DOI: 10.1016/j.chemosphere.2018.05.166

Galvao L. y Corey G. (1987). Serie Vigilancia 5. Cromo. Centro Panamericano de Ecología Humana y Salud, Organización Panamericana de la Salud, Organización Mundial de la Salud. Metepec, México, 66 pp.

Gómez-Bertel S., Amaya-Bulla D., Maldonado-Saavedra C., Martínez-Salgado M.M., Quevedo-Hidalgo B., Soto-Guzmán A.B. y Pedroza-Rodríguez A.M. (2008). Evaluación de tres hongos lignolíticos y de Aspergillus niger como alternativa para el tratamiento de aguas residuales del curtido de pieles. Rev. Int. Contam. Ambie. 24 (3) 93-106.

Guillamón J.M. y Barrio E. (2017). Genetic polymorphism in wine yeasts: Mechanisms and methods for its detection. Front. Microbiol. 8 (806), 1-20.

DOI: $10.3389 / \mathrm{fmicb} .2017 .00806$.

Huang F., Wang Z. H., Cai Y. X., Chen S. H., Tian J. H. y Cai K. Z. (2018). Heavy metal bioaccumulation and cation release by growing Bacillus cereus RC-1 under culture conditions. Ecotox. Environm. Safe. 157 (15), 216-226. DOI: 10.1016/j.ecoenv.2018.03.077

Kanagaraj J., Babu N. C. y Mandal A. B. (2008). Recovery and reuse of chromium from chrome tanning wastewater aiming towards zero discharge of pollution. J. Clean. Prod. 16 (16), 1807-13.

DOI: $10.1016 /$ j.jclepro.2007.12.005

Khamis M., Jumean F. y Abdo N. (2009). Speciation and removal of chromium from aqueous solution by white, yellow and red UAE sand. J. Hazard. Mater. 169 (1), 948-952. DOI: 10.1016/j.jhazmat.2009.04.053
Lefebvre O. y Moletta R. (2006). Treatment of organic pollution in industrial saline wastewater: a literature review. Water. Res. 40 (20), 3671-3682.

DOI:10.1016/j.watres.2006.08.027

Leyva R., Guerrero R.M., Fuentes L. y Mendoza J. (2000). Remoción de cromo hexavalente y trivalente de solución acuosa por medio de resinas de intercambio iónico. Información tecnológica 11 (3), 93-100.

Loarte A.D. y Sanabria V.R. (2015). Efecto del pH y tipo de adsorbente en la remoción de manganeso de aguas superficiales contaminadas por relaves mineros. Tesis de Licenciatura, Facultad de Ingeniería Química, Universidad Nacional del Centro de Perú. Huancayo, Perú, 140 pp.

Madhavi V., Reddy A.V., Reddy K.G., Madhavi G. y Prasad T.N. (2013). An over view on research trends in remediation of chromium. Research Journal of Recent Sciences 2 (1), 71-83.

MADS (2015). Resolución 0631 de 2015. Parámetros y valores límites máximos permisibles en los vertimientos puntuales a los cuerpos de aguas superficiales y a los sistemas de alcantarillado público y se dictan otras disposiciones. Ministerio de Ambiente y Desarrollo Sostenible. Diario oficial de Colombia.18 de abril de 2015.

Moreno-Benavides J.A., Peña-Salamanca E.J y BenítezCampo N. (2019). Reducing Cr6+ in electroplating wastewater with Bacillus cereus strain B1. Universitas Scientiarum. 24 (1), 73-89, 2019.

DOI: $10.11144 / J a v e r i a n a . S C 24-1 . r c i e$

Okeke B.C. (2008). Bioremoval of hexavalent chromium from water by a salt tolerant bacterium, Exiguobacterium sp. GS1. J. Ind. Microbiol. Biot. 35 (12), 15711579. DOI: $10.1007 / \mathrm{s} 10295-008-0399-5$

Ortega N., Delgado J.E. y Corzo L. (2001) Plan de manejo ambiental curtiembres el Progreso Municipio de Belén Nariño. Tesis de Licenciatura, Facultad de Ingeniería, Universidad Cooperativa de Colombia. Pasto, Colombia, $63 \mathrm{pp}$.

Palková Z., Janderová B., Zikánová B., Pospísek M. y Forstová J. (1997). Ammonia mediates communication between yeast colonies. Nature 390 (6659), 532-536. DOI: $10.1038 / 37398$

Pellón A., Rodríguez M., Díaz O.G. y Frades J. (2011). Remoción de cromo mediante el uso de un biorreactor utilizando Scenedesmus obliquus inmovilizado. Revista de Ingeniería Hidráulica y Ambiental 32 (1), 13-20.

R Core Team (2014). R: A language and environment for statistical computing. R Foundation for Statistical Computing, Viena, Austria [en línea]. http://www.Rproject.org/ 
Ramírez A. y Benítez-Campo N. (2013). Tolerancia y reducción de cromo (VI) por Bacillus cereus B1, aislado de aguas residuales de una curtiembre. Revista de Ciencias 17 (2), 51-63.

Rao A., Bankar A., Kumar A.R., Gosavi S. y Zinjarde S. (2013). Removal of hexavalent chromium ions by Yarrowia lipolytica cells modified with phyto-inspired Fe 0/Fe 3 O 4 nanoparticles. J. Contam. Hydrol. 146, 63-73.

DOI: 10.1016/j.jconhyd.2012.12.008

Reid E., Liu X. y Judd S.J. (2006). Effect of high salinity on activated sludge characteristics and membrane permeability in an immersed membrane bioreactor. Journal of Membrane Sci. 283 (1), 164-171.

DOI: $10.1016 /$ j.memsci.2006.06.021

Roberts M.F. (2005). Organic compatible solutes of halotolerant and halophilic microorganisms. Saline systems 1 (1), 1-5.

DOI: $10.1186 / 1746-1448-1-5$

Saavedra J.I. (2017). Determinación espectrofotométrica simultánea de Cr (III) y Cr (VI), por regresión lineal multivariante (RLM), y su uso en la evaluación de biorremediación de cromo en aguas con la levadura Yarrowia lipolytica. Tesis de Licenciatura, Facultad de Ciencias Naturales y Exactas, Universidad del Valle. Cali, Colombia, 10 pp.

Sanz M., Siebel M., Ahlers R. y Gupta J. (2016). New approaches to cleaner production: applying the SASI method to micro-tanneries in Colombia. J. Clean. Prod. 112, 963-971.

DOI: $10.1016 /$ j.jclepro.2015.08.090

Sharma S y Adholeya A. (2011). Detoxification and accumulation of chromium from tannery effluent and spent chrome effluent by Paecilomyces lilacinus fungi. Int. Biodeterior. Biodegrad. 65 (2), 309-317.

DOI: $10.1016 /$ j.ibiod.2010.12.003
Sepehr M.N., Nasseri S., Zarrabi M., Samarghandi M.R. y Amrane A. (2012). Removal of Cr (III) from tanning effluent by Aspergillus niger in airlift bioreactor. Sep. Purif. Technol. 96, 256-262.

DOI: 10.1016/j.seppur.2012.06.013

Shinde N.R., Bankar A.V., Kumar A.R. y Zinjarde S.S. (2012). Removal of Ni (II) ions from aqueous solutions by biosorption onto two strains of Yarrowia lipolytica. J. Environ. Manage. 102, 115-124.

DOI: 10.1016/j.jenvman.2012.02.026

Silverman M.P. y Lundgren D.G. (1959). Studies on the chemoautotrophic iron bacterium Ferrobaccillus ferooxidans: An improved medium and a harvesting procedure for securing high cell yields. J. Bacteriol. 77, 642-647.

Sundar V.J., Raghava R. y Muralidharan C. (2002). Cleaner chrome tanning emerging options. J. Clean. Prod. 10 (1), 69-74.

Vicente M.S. (2006). Uso de bacterias sulfato-reductoras inmovilizadas para la precipitación de metales pesados. Trabajo final de Laboratorio de Procesos Biotecnológicos, Facultad de Ciencias Exactas, Universidad Nacional de la Plata, Buenos Aires, Argentina, 61 pp.

Viti C., Pace A. y Giovannetti L. (2003). Characterization of $\mathrm{Cr}$ (VI)-resistant bacteria isolated from chromiumcontaminated soil by tannery activity. Curr. Microbiol. 46 (1), 1-5. DOI: 10.1007/s00284-002-3800-z

Vylkova S., Carman A.J., Danhof H.A., Collette J.R., Zhou H. y Lorenz M.C. (2011). The fungal pathogen Candida albicans autoinduces hyphal morphogenesis by raising extracellular pH. MBio. 2 (3), 00055e-11. DOI: $10.1128 / \mathrm{mBio} .00055-11$

Yun Y.S., Park D., Park J.M. y Volesky B. (2001). Biosorption of trivalent chromium on the brown seaweed biomass. Environ. Sci. Technol. 35 (21), 4353-4358. DOI: $10.1021 / \mathrm{es} 010866 \mathrm{k}$ 